\title{
Research on United Account Payment Platform Technology for Smart Transportation
}

\author{
Hua PAN
}

\begin{abstract}
In order to integrate the account information of many enterprises in the transportation industry group, this paper proposes a solution of united account payment platform, provides multi-channel and united payment services. The program studies united account payment management technology. It realizes the integration of account information of many corporate groups, which provides united fund account information management. Through the establishment of a united account management center, the system interactively processes the account contents of all group businesses, and completes centralized management, behavior analysis, and united authentication of enterprises and individuals. It also provides single sign-on and account association for each application module and function scenario of the enterprise. Through the establishment of a united payment management center, this paper realizes united management of multiple payment methods and united management of payment channels provided by access payment institutions. By managing the payment center routing rules, the system controls the categorization of downstream payment channels. Finally, the feasibility and effectiveness of the technology are verified through the implementation of the united account payment management system.
\end{abstract}

Keywords: information fusion; payment platform; smart transportation; united account

\section{INTRODUCTION}

With the rapid development of China's economy, personal mobile phone users have been greatly popularized. The mobile payment has also developed rapidly. Its security and convenience have made mobile payment quickly cover all areas, including transfer and remittance, online shopping, self-service payment, mobile phone bill, public transportation, personal finance, and so on. According to the "Overall Situation of the Payment System Operation in the Q3 of 2018" issued by the People's Bank of China on November 19, 2018, the banking financial institutions handled 45.236 billion electronic payment services in the Q3 of this year, which is amounting to 592.43 trillion yuan. Among them, the mobile payment business was 16.935 billion, with an amount of 65.48 trillion yuan, which increased by $74.19 \%$ and $32.91 \%$ respectively. As a result, mobile payment has become an important means of public payment without any doubt.

In recent years, China's modern payment and settlement system has received more attention, the national, regional and industry payment clearing system has emerged. The continuous enrichment of external clearing channels and the direct payment of electronic payment processing methods have become a new feature in the payment field. At present, many enterprises serving the public in the transportation field have not united their user accounts, and they are still in their respective decentralized service stages. It is urgent to integrate different electronic payment methods of their respective enterprises, which realize united management of financial information and lay a foundation for building the basis of "smart transportation".

At present, there are several payment platforms in the domestic transportation field. The main platforms are as follows:

UnionPay cooperated with China CRRC and jointly invested in the establishment of a high-tech mixed ownership enterprise - BWTON Technology Co., Ltd. (referred to as "BWTON "). BWTON realizes the interconnection and interoperability of multi-mode vehicles, and is committed to provide users with a total solution for smart travel with no-wait, no-payment, and nodistance service.

Alipay has already supported 2-dimensional bar code in buses in many cities across the country. At present, Alipay is promoted through cooperation with all-purpose card, and it can be unimpeded across the country.

Tencent obtained the ride code through its WeChat applet. From November 23, 2017, the WeChat payment service function will be launched on the Customer Service Center of 12306 China Railway. In March 2018, the license plate is equal to payment code, WeChat directly launched "high-speed e-line".

The Q6 intelligent full payment consumer terminal independently researched and developed by Gongtongtong Technology has become the first full-service payment terminal for Android in large-scale operation in China. It has mobile phone NFC, UnionPay card, mobile phone PAY, Ministry of Communications card, Ministry of Construction card, Full support for all payment methods such as Tianjin One Card, Alipay Scan Code, and WeChat Scan Code.

\section{THE OVERALL DESIGN OF THE PLATFORM 2.1 System Design}

The theoretical research is as follows: Literature [1] proposed a highway toll system, which uses the vehicle license plate recognition to obtain vehicle information, and pays the highway fee through mobile payment, which provides a new idea for the highway to achieve the development goal of uninterrupted charging. Literature [2] researched on the workflow of vehicle license plate recognition technology equipment, and the specific application in high-speed toll shows that the automatic vehicle license plate recognition in the highway toll collection reduces the workload of the staff and improves the traffic volume of the expressway. Literature [3] proposed an expressway non-stop mobile payment platform based on the Internet of Things, which relieved the pressure on the operation and maintenance of expressway operations and improved the user experience. Literature [4] starts from the concept and characteristics of mobile payment, discusses its application design and basic 
composition in highway toll collection, and provides theoretical support for realizing mobile payment in highway toll system. Literature [5] explores the advantages and disadvantages of several representative toll mobile payment schemes, which have emerged in China, and it provides reference basis for expressway decision-making departments. Literature [6] combines the current situation of mobile payment construction in China's highway toll collection, studies the application of mobile payment in the highway toll field from different dimensions, compares and evaluates each mobile payment form, and provides technical decision for highway operation management. Literature [7] discusses the groundbreaking "Intelligent Redundant Vehicle license plate recognition Technology", which provides a powerful back-office guarantee for highway inspection and escape operations. Literature [8] explores the highway non-stop mobile payment system from the aspects of key technologies, system characteristics, and application promotion, which discusses how to cope with the emergence of new Internet + technology, and enriched charging scenarios from the perspective of highway operators. The new challenges are encountered by highway tolls. In the application field, the literature [9] has designed the new expressway non-stop charging comprehensive control system based on the network payment platform, which is beneficial to speed up the process of highway toll collection and the sustainable development of expressways. Literature [10] proposed that the ETC system should introduce "Internet +" thinking, continue to innovate, improve and optimize in terms of service, payment and application, and provide guidance for the research of this paper. Literature [11] introduced the application of mobile Internet payment in highway charging scenarios under the background of "Internet +", and put forward corresponding technical implementation opinions. The problems of non-cash charges on the expressway, mobile internet payment schemes and mobile internet payment are introduced. Literature [12] introduced the research and implementation of China UnionPay mobile payment from the perspective of system engineering. Through the analysis of the characteristics and engineering difficulties of the project, the general requirements and core engineering problems of mobile payment projects are summarized, and the integration of innovative technologies is introduced to solve the contradiction between ease of use and security. Literature [13] takes Hubei Province as an example to discuss the application and prospect of mobile payment technology in the expressway industry. Different from other provinces, when considering the mobile payment of expressways, Hubei Province fully considers and studies the characteristics and users of various payment methods, and proposes the goal of supporting as many payment methods as possible, and considers all from the whole network. Literature [14] introduced the technical scheme and application of the highway non-stop mobile payment system in Shandong Province, analyzed the main performance and characteristics of the system, and introduced the application of the system. In Literature [15], the necessity of introducing mobile payment from the three dimensions of public travel, industry management, and social development trend was discussed and analyzed.
Combined with the reality of highway mobile payment in Hubei Province, the implementation and system solution of highway mobile payment was proposed. The scheme model of highway mobile payment system was constructed and the model was analyzed. Literature [16] explores the necessity and feasibility application of mobile payment in highway tolls, and proposes the industry's first scanning code payment technology solution, and introduces the scheme in detail. Based on SIMPass technology, literature [17] developed a mobile payment operation and transaction process plan for highway toll collection, and proposed a modification plan for the existing toll software and electromechanical system when the highway toll system applied mobile payment, realizing mobile payment on the highway. Literature [18] to Literature [20] have proposed the introduction of mobile payment methods to highway tolls, and studied the application of mobile payment on highways. In Literature [21], the highway non-stop mobile payment system is discussed from the aspects of key technologies, system characteristics, and application promotion. From the perspective of highway operators, this paper explores how to cope with the new challenges of highway tolls under the circumstance of new Internet + technology.

The purpose of the unified account establishment is mainly to realize the online transaction payment function in the transportation field, and strive to obtain the user's viscosity to the unified account at the traffic port to meet the public travel payment needs. The system can control the payment provisioning in the transportation field and obtain payment data in the transportation field.

According to the particularity of the transportation enterprise business, the platform design needs to consider the following questions:

(1) A method of implementing a financial independent settlement functions without using a total account number + multiple business accounts. In order to ensure timeliness and efficiency, it is best to deal with it in the same bank.

(2) In order to meet the specific business needs of the Executive Board for Jietong, the designated account needs to be pre-stored in the ETC account, and the remaining amount can be deposited into the bank's total account number.

(3) One card, ETC, and so on can be used as a virtual card. If there is no cash, it is only used as a transaction record. If the card is cancelled, the money will be directly returned to the total account.

(4) United payment allows customers to use the bankcard or each UnionPay card or Alipay, WeChat, which recharge the premium and enter the user's primary account.

The specific design scheme is shown in the figure below.

\subsection{Overall Architecture}

\section{(1) Application architecture}

The system can be divided into service access applications, external service systems, internal management systems, and internal functional applications in application architecture partitioning. The overall system application architecture is as follows: 


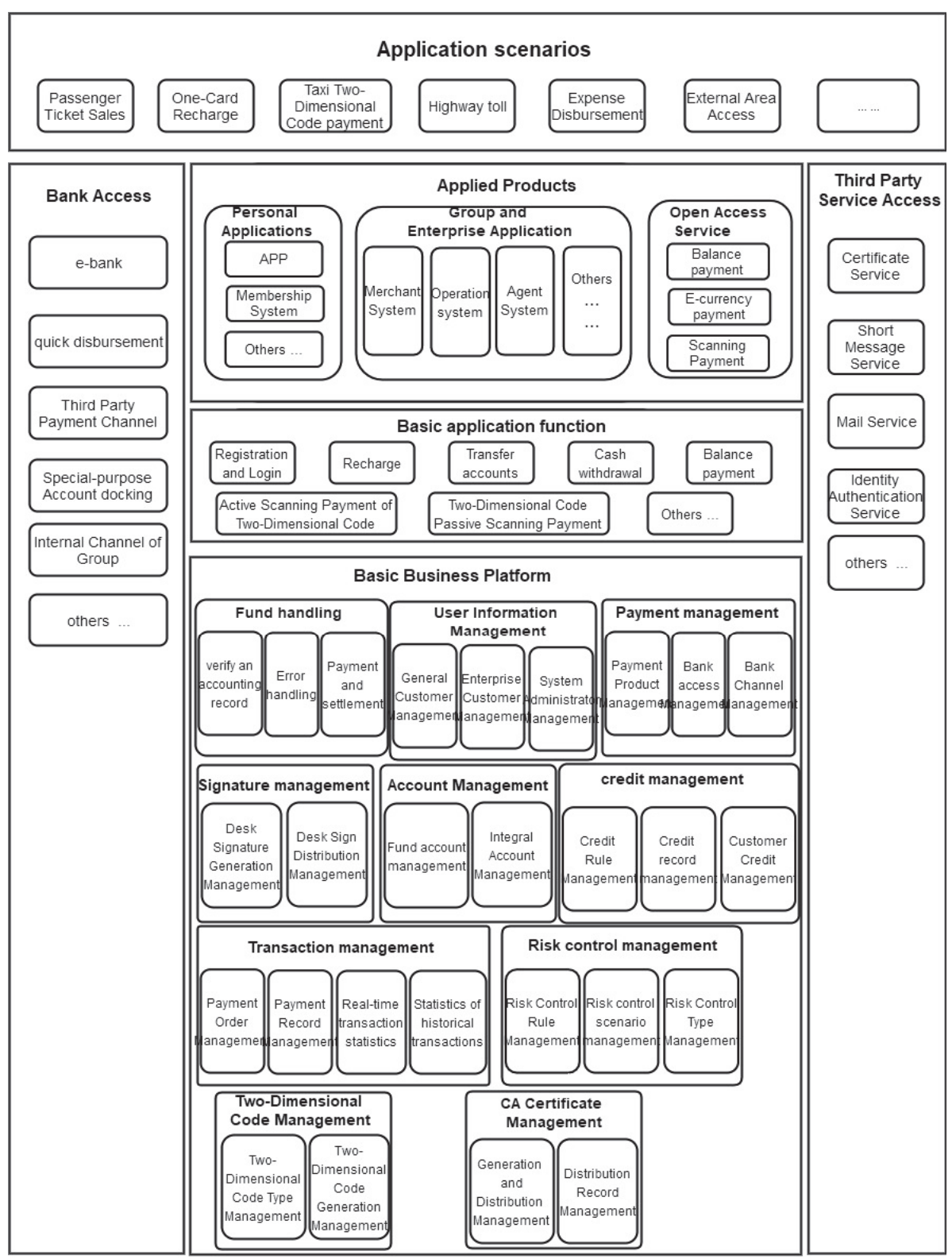

Figure 1 System design

Service access applications include payment gateways and APP pre-location. The payment gateway mainly includes various payment service interfaces packed in the platform, such as the single interface, the balance payment interface, the scan code payment interface, the order inquiry interface, and the bankcard element authentication interface. The APP front-end mainly provides the service function interface, including the user registration interface, the user login interface, the account recharge interface, the account withdrawal interface, the account transfer interface, the 2 - dimensional bar code payment and payment function interface, the user information inquiry interface, the account information inquiry interface, Payment record query interface, and so on.

The external business system includes a membership system and a merchant system. The member system provides PC-based member center self-service functions for individual member users, including member registration, login, real-name authentication, bank card binding and unbinding, recharge, transfer, cash withdrawal, account inquiry, payment record inquiry, personal basic information inquiry, and so on. The merchant system mainly provides united account management functions for the group internal enterprises (Ticket Company, Jietong Company, One Card Company) or institutional merchants, including general ledger inquiry, account detail inquiry, recharge, bulk transfer, withdrawal and other functions.

The internal management system includes the operating system and the agent system (reserved). The operation system is the main control center of the entire payment platform. The core functions include bank channel management, bank payment channel management, payment product management, station sign (receipt 2-dimensional bar code) management, user management, user payment service function setting, and account information inquiry, account detail inquiry, settlement record inquiry, distribution information inquiry, payment order inquiry, income statistics report, authority management, log management and other functions. The agent system (not planned, reserved) is mainly used to expand the business in the agent mode, the agent can maintain the business information under it and view the transaction data, which can view the distribution and the withdrawal of the distribution. 


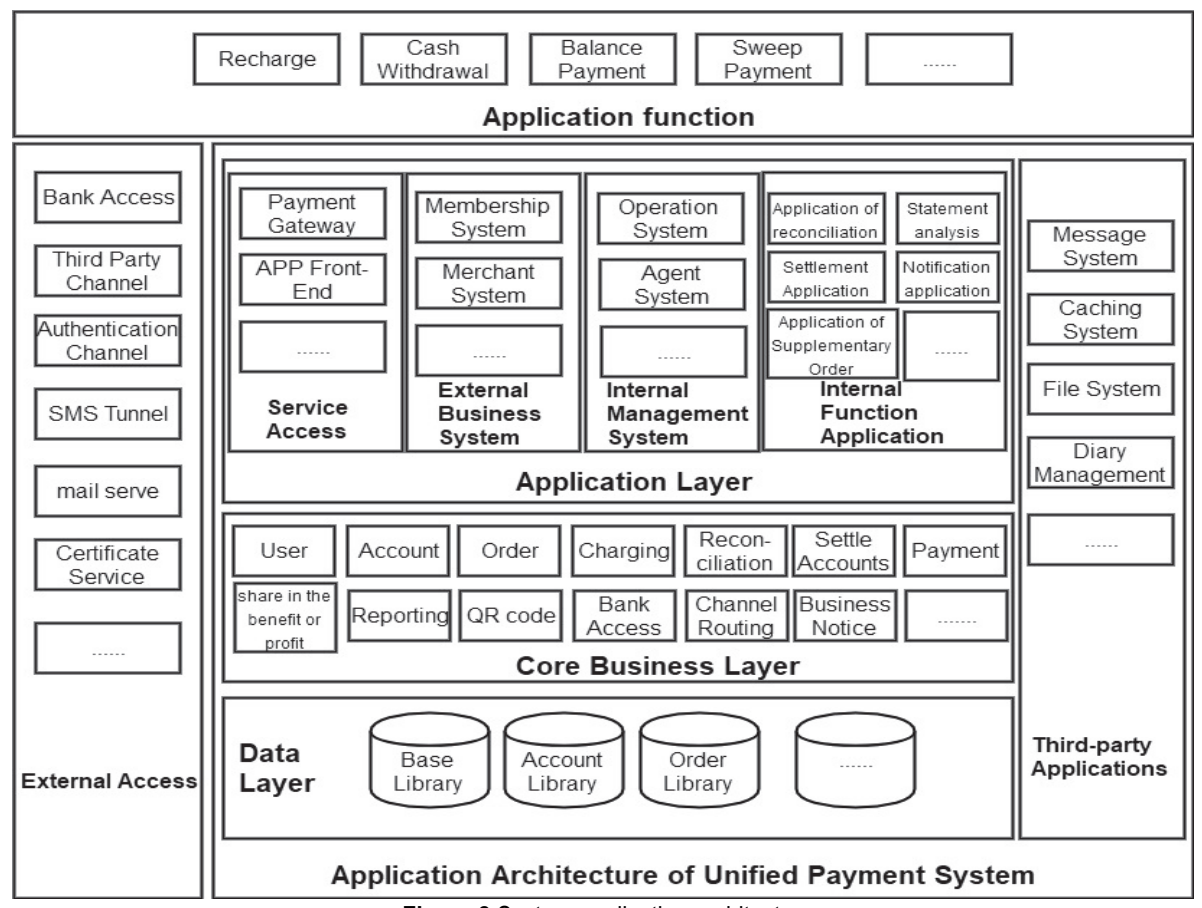

Figure 2 System application architecture

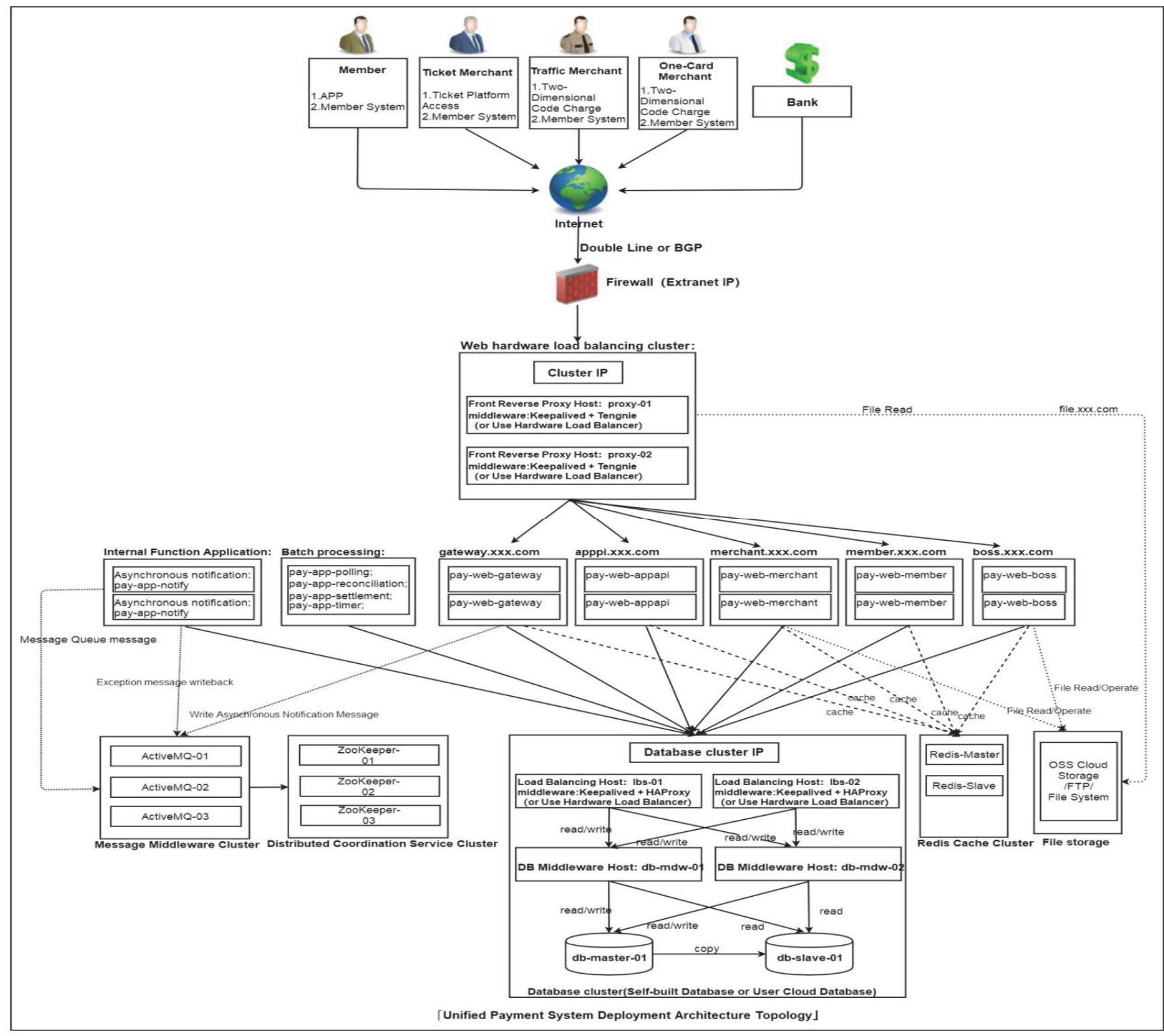

Figure 3 Overall deployment architecture 
Internal function applications include reconciliation application, report analysis and statistics application, settlement application, automatic replenishment query application, merchant notification application, and so on.

All applications share the same core business layer, and the core business layer engineering also has a detailed modular planning. The core business layer module functions include user, account, order (transaction), transaction cost and revenue accounting statistics, reconciliation, settlement, payment, distribution, reporting, bank channel access, channel routing, merchant notification, permissions, etc.

(2) Deployment architecture

The system is deployed in a cluster architecture. All applications or middleware are deployed with highavailability clusters of two or more nodes to ensure high availability and flexible maintainability. The overall deployment architecture of the system is as follows:The business database adopts a MySQL read-write separation cluster with one master and multiple slaves to ensure data security and ensure good performance of the data cluster.

Hotspot data or global configuration data in the system can be stored and managed by using a cache. The distributed cache adopts a master-slave Redis cluster or a multi-master multi-slave 6 - node Redis cluster, which can effectively ensure the security and availability of cached data. In addition, the Redis cluster needs to enable password verification, which opens only to the intranet of the platform (indirectly open to the external network) to improve the security of the cache cluster.

The message middleware is required for merchant notification and message subscription in the system. The distributed message middleware adopts a 3 - node ActiveMQ cluster, which can effectively ensure the high availability of the cluster, thereby ensuring the reliability of the message data. The ActiveMQ cluster relies on ZooKeeper, so it is necessary to deploy a 3 - node ZooKeeper Distributed Coordination Service cluster synchronously.

Member data and merchant data in the system need to store. FTP used to storage plus regular backup mode for management. FastDFS used to build a distributed file system for storage.

Except for some batch task applications that do not have high availability requirements, all other applications need to deploy two nodes or multiple nodes. The application deployment environment is deployed using CentOS7, JDK7 (or JDK8), and Tomcat8. Tomcat8's application log should be configured to cut the log by day, avoiding the single log file being too large and difficult to maintain.

The Web Reverse Proxy uses the latest stable version of Alibaba's open source Tengine (Nginx Improvement). Use Tengine to implement load balancing request forwarding for Tomcat clusters. The high availability of Tengine middleware can be secured by using a hardware load balancer for routing or using Keepalived to implement Tengine's active/standby switchover.

(3) Network topology and network access control

The implementation of the network topology is as follows:

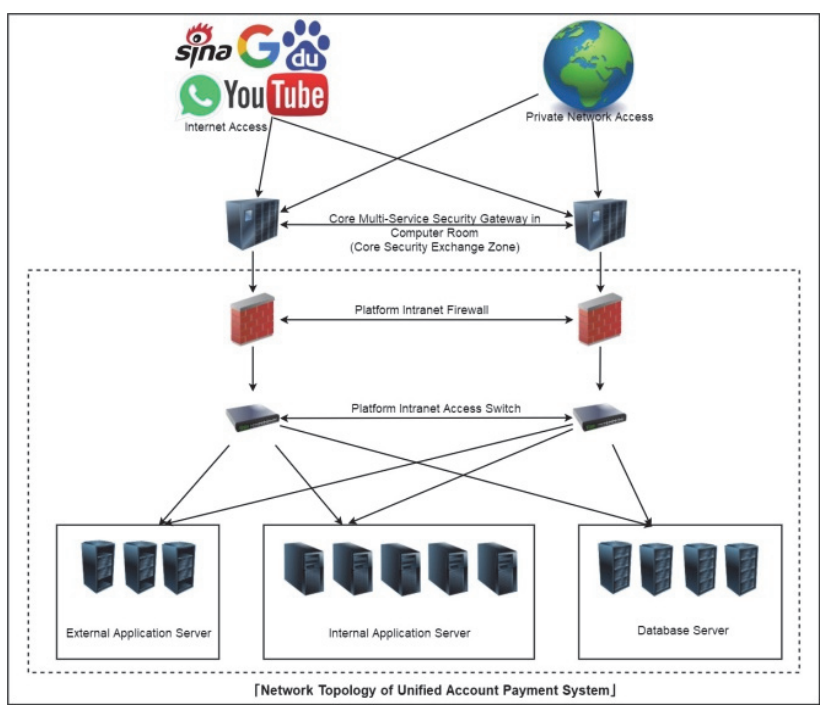

Figure 4 Network topology

As shown in the above figure, the equipment in the dotted line box belongs to the proprietary equipment of the united account payment system, which is composed of the platform intranet firewall, the platform intranet core switch, the external application server, the internal application server and the database server.

All types of devices use independent network segments for IP address allocation and control network access among network segments. The specific network access rights are controlled as follows.

- To manage the device through the terminal or the network, or log in to the operating system through SSH, the device needs to log in, which has access to the intranet of the platform to operate the device or system.

- On the application connection, the database server can only be accessed by the internal application server (the external application server cannot access the database server), and the database server cannot be accessed by the external network, which cannot access the external network.

- On the application connection, the internal application server can be accessed by the external application server. The internal application server cannot be accessed by the external network but can access the external network as needed (such as requesting a bank or sending a notification to the downstream platform). The internal application server is used to deploy all development applications (service access applications, external business systems, internal management systems, and internal functional applications) and dependent third-party middleware (cache systems, messaging systems, and file systems) in the system.

- On the application connection, the external application server can be accessed by the external network, but only a specific port (such as port 80) is opened. The external application server can access the external network as needed. The external application server is used to deploy the Web reverse proxy service, and access the web application or file service in the internal application server through the reverse proxy service.

- Application access and communication mode of the system corresponding to the above network access control: - The application deployed in the internal application server communicates with the database, the cache system, 
the message system, and the file system by TCP protocol.

- The Web Reverse Proxy Service deployed in the external application server accesses the web application or file service in the internal application server through HTTP.

- Applications that need to open the Internet (service access applications, external business system applications, and file resources in file services) must have configured to allow external networks to access HTTPS. For internal management system applications, access is required through VPN.

\subsection{Account Management Center}

The account system is the core module of the united account system of the card company, which mainly includes the following contents:

(1) Corporate account: Corporate account refers to the virtual fund management account registered with the company in the name of the enterprise, which needs to add through the operation background. The enterprise account corresponds to the group enterprise customer in the user system. When the enterprise account is added, a super administrator is used to manage the group enterprise account by default. At the same time, in the operation background, the group enterprise client can also be bound by adding the binding form of group corporate account. Group corporate customers and group corporate accounts are one-to-many relationships. Different group corporate customers can have different rights to operate group corporate accounts. The binding relationship between the group enterprise customer and the group enterprise account needs to review before it can take effect.

(2) Ordinary account: It is a virtual fund management account corresponding to the internal customers and external customers of the group. A normal account has a one-to-one relationship with a customer. That is a customer that can only have one account. Customers have the right to recharge, trade, withdraw, query and other related operations on their own accounts.

The main process of account business application is as follows.

(1) Account addition process

The group enterprise account is the account of the enterprise company under the card company in the united account system, and the account added by the operator in the background of the system.

The group enterprise account adding function is mainly provided to the system administrator to add the registered account of the group internal enterprise. After the successful addition, it needs to be reviewed and confirmed by the system auditor before it can take effect. At the same time as generating the group enterprise account, a super management customer is generated synchronously as the highest management customer of the enterprise account.

The process of adding a group enterprise account is shown in the following figure.

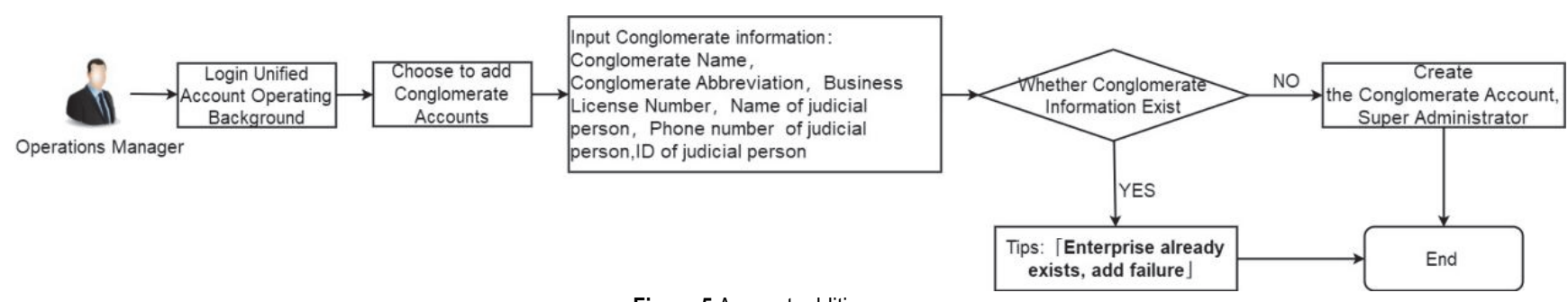

Figure 5 Account addition process

(2) Recharge process

The united account system will provide recharge function so that customers can recharge the fictitious account through E-bank, Express payment, or third party channels, and then make other consumption through the balance of the fictitious account.

The recharge function is mainly used to provide customers with E-bank, Express payment or third-party channels for account balance refill. This function needs to call a bank or a third-party payment channel. In the communication process, it is necessary to ensure the legality of signing and encryption of communication messages with banks or third-party channels to ensure the security of funds.

The specific recharge process is shown in the following figure.

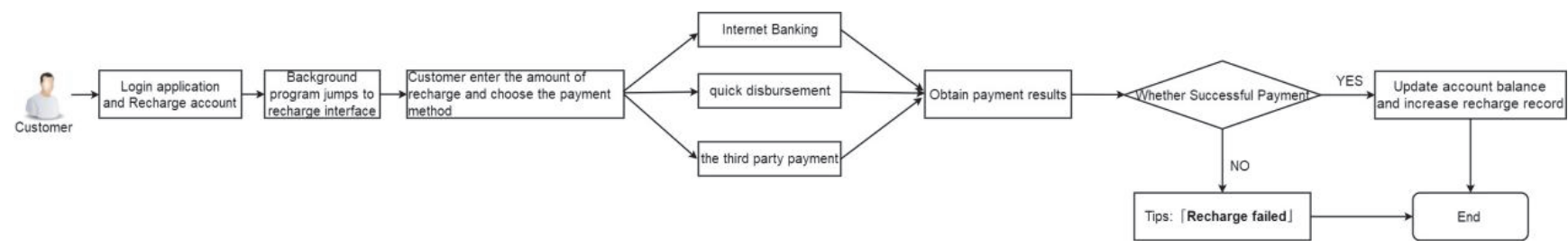

Figure 6 Customer recharge flow chart

(3) Cash withdrawal process

In the case that the customer's fictitious account has a balance, the customer can withdraw the account balance to the debit card through the withdrawal function.

The cash withdrawal function is mainly used to provide the customer with the cash withdrawal balance in the account to the personal debit card. This function needs to call the bank or a third-party payment channel. In the communication process, it is necessary to ensure the legality of signature and encryption of communication messages with the bank or third party channels to ensure the security of funds. 


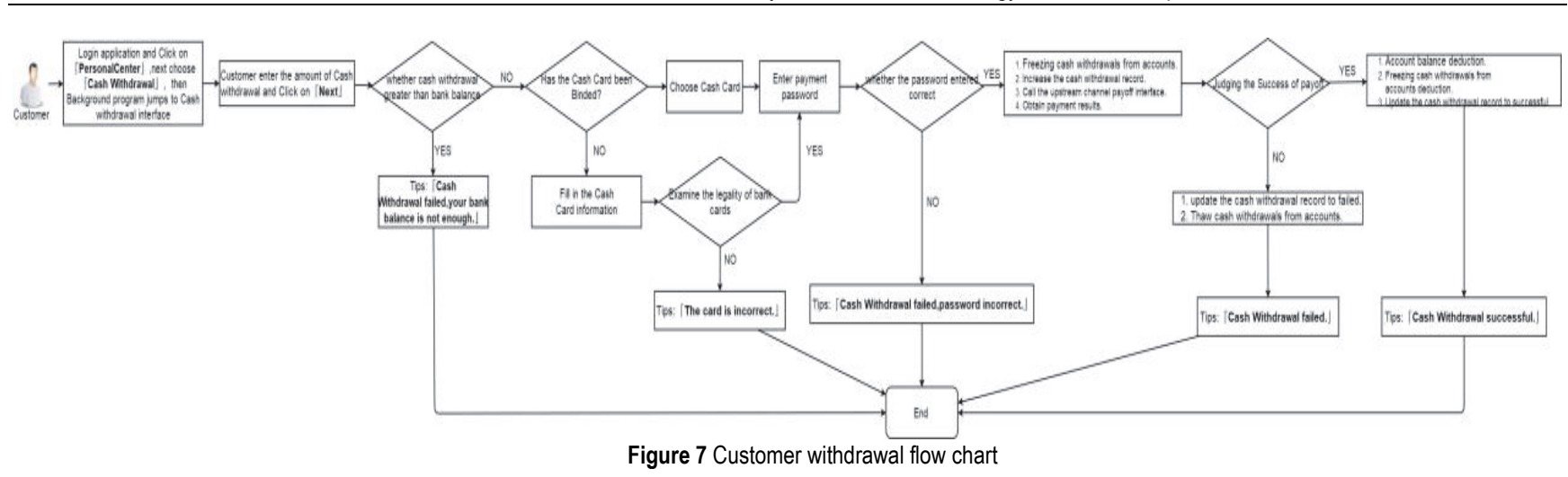

(4) Transfer process

The transfer function is used to transfer funds among fictitious accounts. After customer A logs in to the united account, the funds of the fictitious account balance in the account can be transferred to customer B. At the time of transfer, Customer A needs to enter the transfer amount and pay only the password, the system-trading day transfer limit.
The transfer function is mainly used to provide the customer with the available balance in the account to be available to others. This function involves the increase and decrease of two accounts and the increase of transfer records and collection records. All accounting-processing needs to be done within the same transaction. The accuracy of account balance needs to make define. During the transfer process, the one-day transfer limit for the transferred account needs to verify.

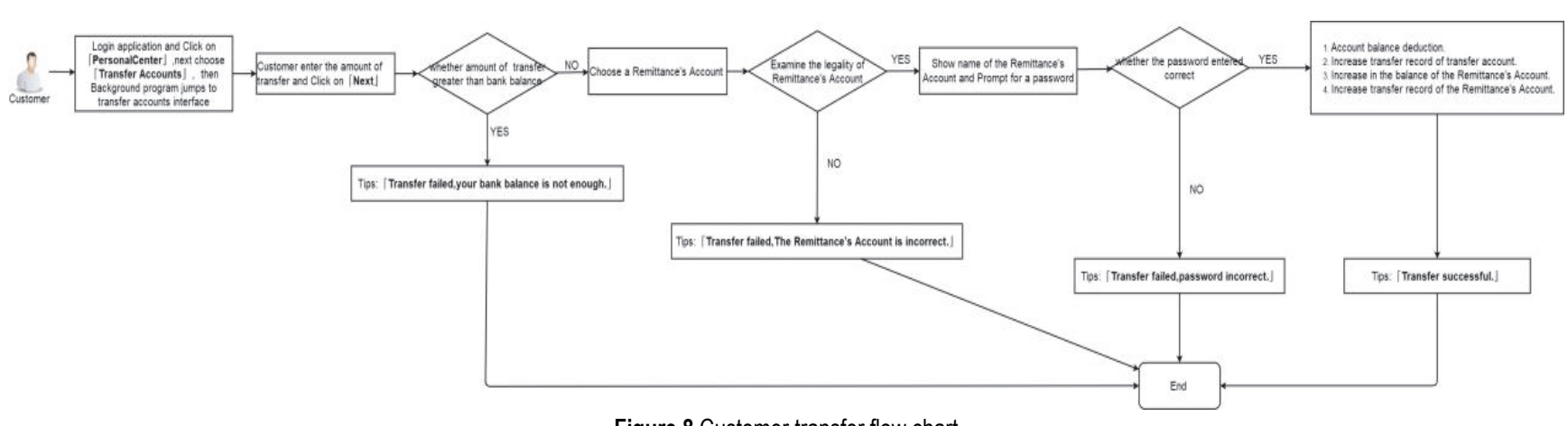

Figure 8 Customer transfer flow chart

\subsection{Payment Management Center}

The Payment System is a financial arrangement consisting of an intermediary that provides payment and clearing services and a professional technical means to realize payment instruction delivery and fund settlement. It is used to realize the settlement of creditor's rights and debts and the transfer of funds. Sometimes it is also called liquidation.

The card company payment is an integrated payment system that integrates payment and clearing without the qualification of liquidation. Mainly it is divided into two.

(1) Providing payment capabilities for companies under the card company, other partner companies, internal customers, and external customers includes multiple payment methods. Mainly Alipay's main sweep, and being swept, WeChat's main sweep, and being swept, WeChat public account, QQ wallet payment, Jingdong wallet payment, UnionPay QR code payment, bank card Express payment, bank card B2C payment, transfer, balance payment.

(2) Funds clearing and settlement functions provided for the characters of the company, other partner companies, internal customers, and external customers. It should be noted that because the card company does not have liquidation qualifications, the final settlement party is in the upstream bank or other clear settlement qualification platform, and the card company acts as the settlement instruction initiator in this process.

The payment system includes a plurality of functional subsystems such as an operation subsystem, an enterprise customer subsystem, an agent subsystem, a payment gateway system, a subsystem of payment channel access, and a reconciliation settlement subsystem.

Operation Subsystem: It is the operation and management background of the entire payment system. According to the control of the authority point, different operators have different access rights. The whole system includes customer management, transaction order management, bank channel management, account management, and reconciliation management, or other core modules.

Enterprise customer subsystem: This system is mainly for providing enterprise customers with relevant data of their company's platform in the card company, including transaction data, account data, which can also transfer and withdraw cash.

Payment gateway system: The system provides various payment channel interfaces, and provides specific business modules for specific enterprises, so that each enterprise's own business has the ability to pay and collect money. The gateway may provide different APIs according to different payment types. 


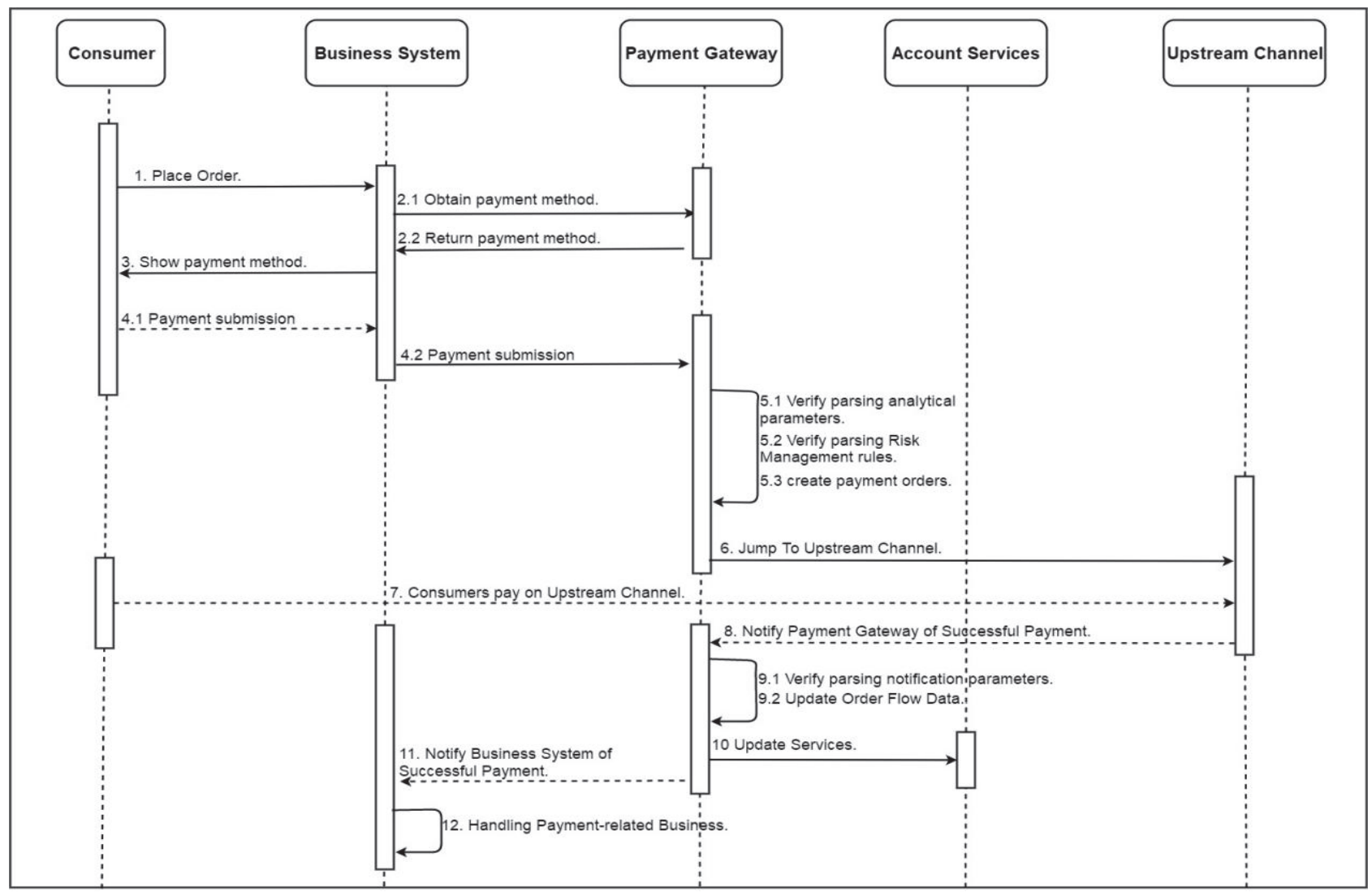

Figure 9 Payment process

Payment channel access subsystem: This system is an access system for the card company's aggregation payment system to dock the bank or the payment channel of the third party payment system. Only through this system to connect the channel to the card company, the group has the ability to provide payment capabilities to its subsidiaries or cooperative enterprises. The company provides the ability to pay.

The main processes of the payment business are as follows:

(1) Payment process,

(2) Cash flow chart,

(3) Reconciliation process.

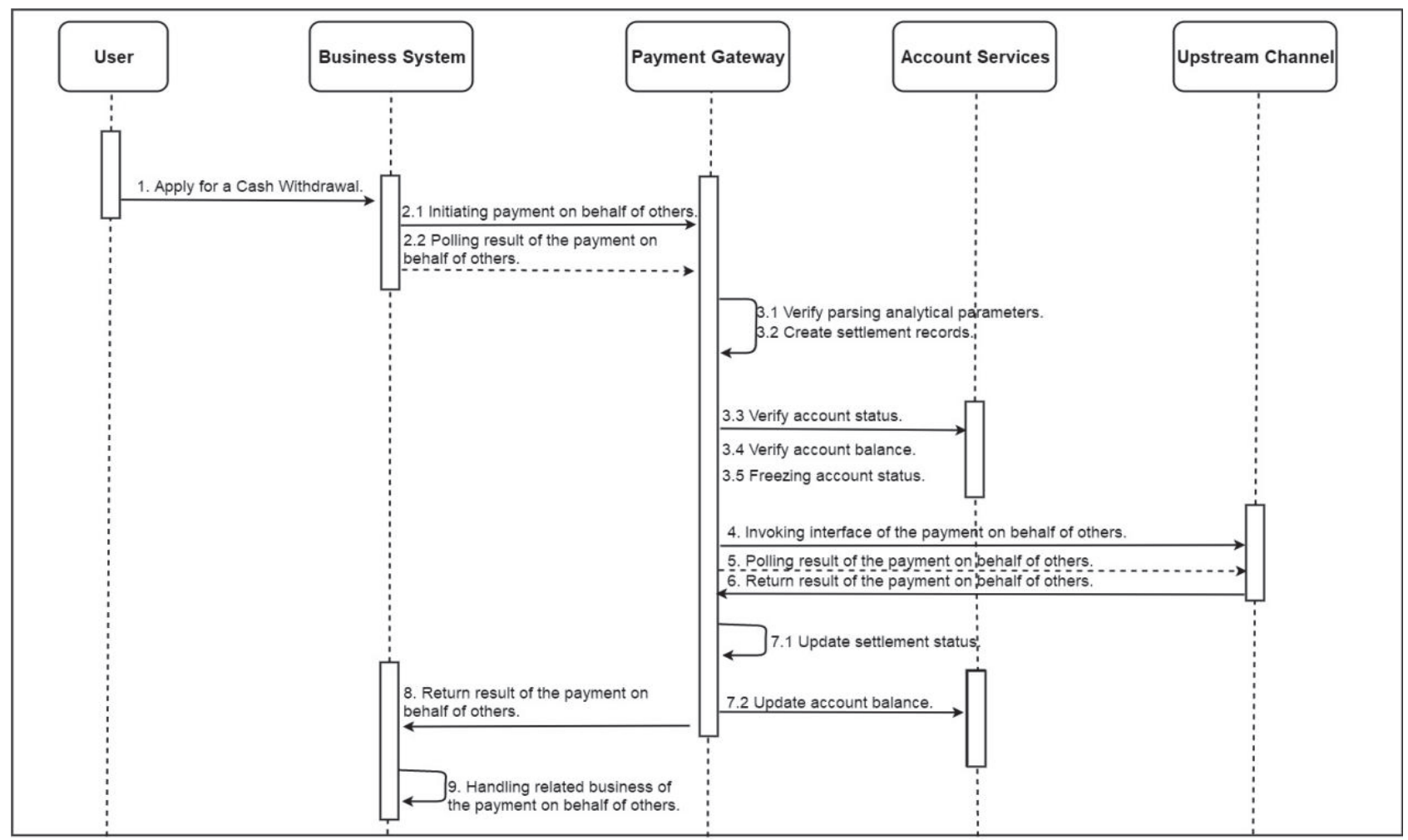

Figure 10 Cash flow chart 


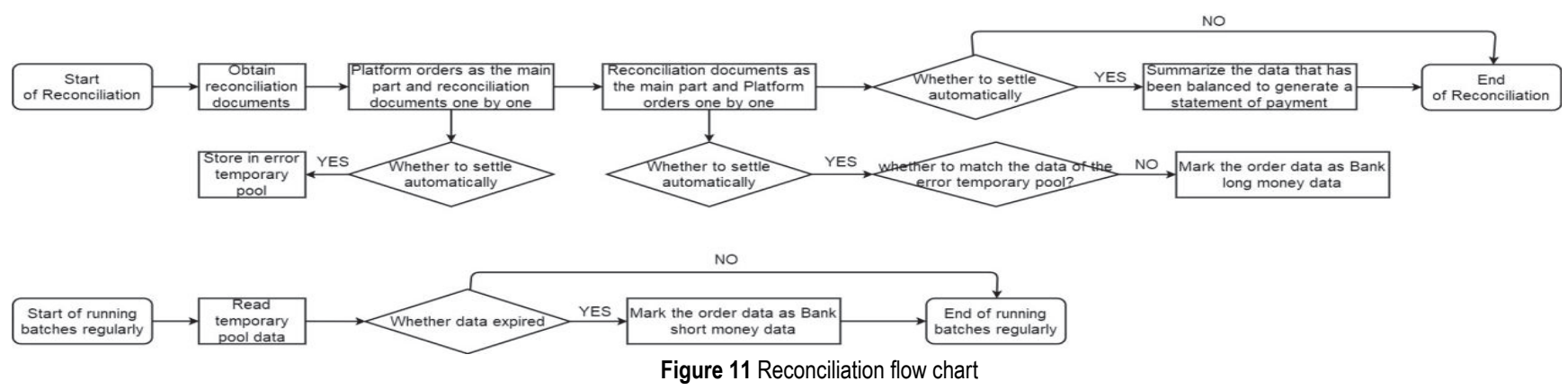

\section{SPECIFIC APPLICATION}

Businesses such as cartoons, Jietong, and ticket pass should be able to configure or add access systems without modifying the code. For example, the Chinese Academy of Sciences should be able to access the system and be able to configure access.

The business relationship of enterprise accounts, enterprise applications, and application products is shown in Fig. 12.

Application management: Enterprise operations personnel can maintain applications on demand in the merchant system, including application additions, application, and enterprise account binding, unbinding, and application auditing. The operation and management personnel of the payment platform can query the application of each enterprise in the operation system, and can freeze and unfreeze the application of the enterprise.

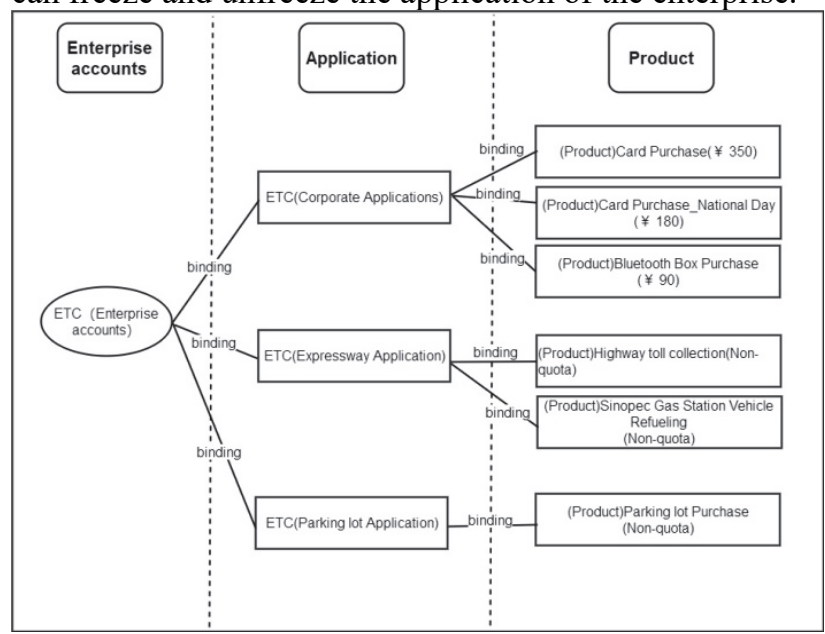

Figure 12 Product business relationship

Product management: Enterprise operations personnel can maintain application products on-demand in the merchant system, including new products (which can be fixed products that are input when the payment is made), product and application binding, unbinding, product check. The operation and management personnel of the payment platform can query the application products of each enterprise in the operation system, which can perform maintenance operations such as freezing and thawing of the application products of the enterprise.

The relationship between the account and the application is a one-to-many relationship, and the enterprise account can be bound by multiple applications. The relationship between products and applications is a one-to-many relationship, that is, an application can contain multiple products. Through this function, the purpose to achieve is to add dynamic configuration of the group enterprise without modifying the code. The customer can only pay with the selected item, and the product can generate a payment QR code. This feature is similar to the mall, buying and selling, and merchandising.

The payment product is an open product of the payment system, and is a withdrawal of the user's ability to pay within the payment system. The payment processing fee, the distribution channel, the transaction limit, the time limit, and other information are set by the payment method of the payment product.

\section{CONCLUSION}

In smart transportation, designing efficient payment solutions can improve the efficiency of public travel and reduce the risk of cash use. This paper proposes a technical solution of unified account payment platform based on unified account payment management technology. The program realizes the integration of enterprises' account information in the group and provides unified fund account information management. In addition, the solution realizes unified management of multiple payment methods, manages the payment channels provided by the access payment institution, and manages the classification of downstream payment channels by managing payment center routing rules. It was verified under the charging scene of Guangxi Expressway. By supporting WeChat, Alipay and other scan code payment in the artificial lane, the traffic efficiency is greatly improved, the risk of the driver bringing cash is reduced, and the user travel experience is obviously improved.

The research focus of this paper is on supporting flexible third-party payment methods and creating different payment products according to different enterprises. The results prove the effectiveness of the solution. How to control the security problems in the application process of united account payment, improve the ability to deal with security risks by technical means, and ensure the security of user account funds is the next research direction.

\section{REFERENCES}

[1] Qiu, Y., Qin, S., \& Sun, X. (2004). A New Highway Intelligent Toll System Scheme. Computer Engineering and Design, 2004(07), 1080-1081+1115.

[2] Liu, B. (2017). Application of vehicle license plate recognition system in high-speed charging. Electronic Technology and Software Engineering, 2017(08), 75-75. 
[3] Zhang, B. (2017). On-line mobile phone payment platform based on Internet of Things. China Traffic Information, 2017(09), 96-103.

[4] Wang, Q. (2017). Research on the Application of Highway Toll System Based on Mobile Payment. China New Communication, 19(17), 85-86.

[5] Ding, F. (2017). On the mobile payment of highway tolls in China. China Traffic Information, 2017(11), 94-96.

[6] Luo, Q., Yang, B., \& Sun, D. (2017). Application of Mobile Payment in the Field of Highway Tolls. China Traffic Information, 2017(11), 91-93.

[7] Wang, G., Lv, W., \& Chen, L. (2017). Application of intelligent redundant vehicle license plate recognition technology in toll road mobile payment system. China Traffic Information, 2017(12), 95-99+120.

[8] Cao, X. (2018). Analysis of the mobile payment system for highway non-stop. China Traffic Information, 2018(02), $110-112+126$.

[9] Huang, W. (2018). Analysis of Expressway Non-stop Toll System Based on Vehicle license plate recognition and Mobile Payment. China Municipal Engineering, 2018(03), 27-30+116.

[10] Cui, H., Ma, Y., Li, X., \& Jia, J. (2018). Architecture design of a new highway non-stop charging system based on network payment. Highway, 63(05), 201-205.

[11] Pan, Y. (2015). Application of Mobile Internet Payment Technology in Expressway under the Background of "Internet +". Science \& Technology Communication, 2015(16), 52+51.

[12] Yongkai, Z. \& Hongfeng, C. (2017). Research and practice on system engineering management of a mobile payment project . Frontiers of Engineering Management, 4(02), 127137. https://doi.org/10.15302/J-FEM-2017011

[13] Zhangm B, \& Wang, N. (2018). Application of Mobile Payment Technology in Expressway Industry. China Traffic Informatization, 2018(s1), 115-117.

[14] WANG, B., XU, Q., \& XU, M. (2018). Analysis of Non-stop Mobile Payment System in Expressway. China Traffic Informatization, 2018(1): 86-88.

[15] Pan, L. \& Zhang, L. (2017). Research on Highway Mobile Payment Scheme Based on POS Terminal. China Traffic Information, 2017(S1), 138-140.

[16] He, Z., Wang, W., \& Wang, P. (2016). Application Research of Scanning Code Payment Technology in Highway Toll Collection. Oinghai Transportation Science and Technology, 2016(03), 36-40+61.

[17] Lu, X. (2012). Application Scheme of Mobile Payment in Highway Toll Collection. Highway Traffic Science and Technology, 29(S1), 91-95.

[18] Zhang, L. \& Zhang, B. (2017). Application Research of Mobile Payment in the Field of Highway Tolling. Journal of Transportation Management, 2017(5), 43-46.

[19] Wang, Q. (2017). Application Research of Highway Toll System Based on Mobile Payment. China New Communications, 19(16), 85-86.

[20] Zhou, L. \& Liu, Z. (2015). Research on the Application of Mobile Payment in Expressway Toll. China Traffic Information, 2015(1), 70-71.

[21] Cao, X. (2018). Analysis of the mobile payment system for highway non-stop. China Traffic Information, 2018(02), $110-112+126$

\section{Contact information:}

\section{Hua PAN}

Guangxi Transportation Research \& Consulting Co., Ltd., No. 6, Gaoxin 2nd Road, High Tech Zone, Nanning, Guangxi, China E-mail: linqupanhua@yeah.net 